\title{
The Effect of Using Web-Cam Chat on the Undergraduate EFL Learners' Socio-Cultural Competence
}

\author{
Ahmad Mousa Bataineh ${ }^{1}{ }^{*} \&$ Ahmed I. Al-Abdali ${ }^{1}$ \\ ${ }^{1}$ Dept. of Curricula and Instruction, Al-al-Bayt University, Mafraq 25113, Jordan \\ *Corresponding author: Dept. of Curricula and Instruction, Al-al-Bayt University, Mafraq, PO \\ Box 130040, Postal Code 25113, Jordan. Tel: 962-796-400-687 E-mail:amab88@yahoo.com
}

Received: February 1, 2015 Accepted: February 26, 2015 Published: June 1, 2015

doi:10.5296/ije.v7i2.7035 URL: http://dx.doi.org/10.5296/ije.v7i2.7035

\begin{abstract}
This study aimed at investigating the use of web-cam chat as one of the most effective tools of Computer-Mediated Communication (CMC), and measuring its effect on the sociocultural competence of the English as foreign language learners. The sample of the study consisted of 38 undergraduate EFL learners who registered for a Conversational Skills Course at Al-alBayt University during the academic year 2013-2014. However, the chosen sample of the study was of two groups: Group one consisted of (20) students, which was chosen as an experimental group, and group two consisted of (18) students, which was assigned as a control group. Data were collected within 8 weeks and statistical analysis was prepared (T-test, one-way analysis of variance, and Scheffe). To assess the effect of using web-cam chat on EFL learners sociocultural competence, students in both groups sat for a written and an oral test at the beginning of the second semester of the academic year 2013-2014 so as to determine their actual sociocultural knowledge before starting the experiment. After 8 weeks, the same test was administered as a posttest. The results of the study indicated that the experimental group performed better that the control group in the sociocultural aspects of language due to the new method of teaching that is Web-cam chat. The results of the study showed that the experimental group acquired some sociocultural aspects rather than the others. Additionally, the findings of the study revealed that the experimental group students have developed their language skills. This might be due to the effect of web-cam chat through which the experimental groups' students interacted a lot with native speakers of English. Accordingly, a set of recommendations were provided at the end of this study.
\end{abstract}

Keywords: English as a foreign language (EFL), web-cam chat, sociocultural competence 


\section{Introduction}

Technology has changed teachers practices in teaching and learning because the classroom became more student-centred rather than teacher-centred. Moreover, teachers' roles moved from lecturers and experts to collaborators and facilitators. In addition, student roles changed from passive listeners to collaborator and occasional experts. Therefore, educational goals changed from memorization of facts to inquiry, invention, and investigation (Jurist, 1999). Accordingly, the goals of teaching could not be achieved without the help of instructional technologies. These goals in teaching need authentic exposure that can be achieved via language teaching technology.

Accordingly, - computer technologies have dramatically changed the way people gather information, conduct research, and communicate with others worldwide (Wang, 2005, p. 39). Wang added that the best way to learn a language is in an interactive environment. More importantly, computer technologies are powerful and effective tools in language teaching. Moreover, MacKinnon (2002) pointed out that technology can help students develop all kinds of skills from the basic to the higher-order critical thinking ones. Technology can also help to facilitate the knowledge-constructed classroom.

More importantly, Burgoon (2008 cited in Bataineh \& Al-Abdali, 2014) pointed out that the advancement of computer technology and the prevalence of network connections have helped to shift gradually learning setting from the traditional face-to-face classroom to online learning environments, where learners interact with the instructor and with other learners through computer-mediated communication (CMC) technologies, including asynchronous and synchronous communication tools.

In addition, Zsuzsana (2010) explored foreign language learners' interactions in CMC to clarify to what extent CMC actually a useful device foreign language is learning. She examined how Japanese as foreign language learners actually interacted in Internet chat (IC) and reported those L2 learners' strategies in CMC take advantage of distinct linguistic and interactional features of IC. The results indicated that CMC provides potential benefits for learning: facilitating comprehensible and contextualized interaction, learners' self- correction, and collaborative learning environment.

Wang (2005, p. 40) stated,

while language is for communication, the Internet has broken down communications distance barrier. Therefore, students can build up partnerships with learning peers in target languages through the Internet. The main ways of communication on the Internet include e-mail, instant messaging, chat rooms, and bulletin boards. With Yahoo messengers, students can not only send instant messages, but also have audio and video conversations that greatly motivate and improve their speaking and listening abilities.

The use of technology in English as a foreign language (EFL) in learning and teaching has 
included mobile phones, mobile-assisted language learning (MALL), computer-assisted language learning (CALL), CDs, DVDs, films, data shows, IPads, iPods, intranet, Internet, multimedia, etc. These types of technology can be regarded as effective tools in the educational operation.

\subsection{Background of the Study and Statement of the Problem}

Brown (2007, pp. 189-190) pointed out that regarding the interrelatedness of language and culture:

-Language is a part of culture, and culture is a part of language; the two are intricately interwoven so that one cannot separate the two without losing the significance of either language or culture. Similarly, Kramsch (1998) held that language is the main means whereby people conduct their social lives and when it is used in context of communication, it is bound up with culture in various and complex ways. Tang (1999) went even further by equating the concept of language with that of culture. In other words, this author claimed that language is synonymous with culture. More obviously, Kuang (2007) added that language is even regarded as the product of culture, as Muir (2007) asserted that language is just one of the various cultural products. He also added that culture might be defined as the ideas, customs, skills, arts, and tools that characterized a particular group of people in a particular time. It consists of a wide range of human environments, material, achievement, norms, beliefs, and feelings.

Gonen \& Saglam (2012) stated that language and culture are so interwoven that separating one from the other would lose the significance of another. Considering the inseparable interface of culture and language, it is difficult to imagine teaching a foreign language without dealing with its culture. Language reflects culture and is influenced and shaped by it. They also noted that the role of foreign language teachers has gained importance as they serve as a medium to teach both the language and the culture of the foreign language. Therefore, culture does not need to be taught independently from language because studying language directly brings about awareness of the target culture and people's behaviour in that target culture.

Bataineh (2002, p. 14) stated,

man as a social being has developed socially patterned ways of thinking, feelings, looking at things, expressing habits, customs, attitudes, traditions, different ways of liking and disliking, various manners of behaviour, despising and avoiding, and so forth. All these socio-cultural patterns which are necessary to facilitate the process of communication constitute culture when they become typical in one particular community and totally different from those of other communities.

By the same token, Qu (2010) stated that the culture of people, in its broad sense, refers to all aspects of shared life in a community. We grow up in a social group; learn ways of looking at things, doing things, expressing things and solving certain problems in certain ways. We also learn to value some things and despise or avoid other things. These attitudes, reactions, and emotions become part of our ways of life without being conscious of them.

It is evident that language and culture are inseparable. Rivers (1981) claimed that culture 
instruction should have at least seven goals. These include making students aware of the way people act; the effects of social variables such as age, sex, and social class on the way they speak; how people in the target culture conventionally act under different circumstances; being critical about the target language culture; developing skills necessary for locating and organizing materials about the target culture; and developing intellectual curiosity about the target culture and empathy towards its people.

Similarly, Cortes (2007) stated that to be able to understand completely how a language works, it is essential to be familiarised with its cultural background, that is, customs, historical and geographical aspects, traditions, values and the people's ways of thinking. Languages are meaningless without culture, as specific communities speak languages, and they show specific structures to serve the needs of such communities. She emphasized the importance of teaching cultural aspects in foreign language (FL) lessons in order to assist students in achieving full communicative and sociocultural competence. She explained the reason why the cultural aspects are related to the target language, or FL in this case, have to be taught, studied, and connected to the fact that culture and language cannot be understood separately.

Therefore, understanding the relationship between language and culture is important for language learners, users, and for all those involved in language education. For language teachers and learners in general, an appreciation for the differences in opinion regarding the relationship between language and culture can help to illuminate the diversity of views held toward the use of language. Moreover, insight into the various views can assist not only second language learners but also first language users, as the way we choose to use language is not just important for some of us. Such insights also open the door for a consideration of how both language and culture influence people's life perceptions, and how people make use of their preacquainted linguistic and cultural knowledge to assess those perceptions. For all language users, the recognition of how their language affects others can greatly influence the direction and motivation for both language study and interpersonal relationships, and it can add great insight and value to language education, program planning, and curriculum development (Elmes, 2013).

Accordingly, foreign language teachers, supervisors, curricula designers, textbook writers, and methodologists should look for effective techniques that give students a chance to acquire the sociocultural aspect of language efficiently and effectively in an authentic environment, because language and culture are inseparable. Additionally, researchers might be allowed to hypothesize that culture should not be taught inseparably from language; they should be regarded and taught as one. Culture and communication are inseparable because culture does not only dictate who talks to whom, about what, and how the communication proceeds; it also helps to determine how people encode messages, the meanings they have for messages, and the conditions and circumstances under which various messages may or may not be sent, noticed, or interpreted. Therefore, this study will focus on investigating the effect of web-cam chat on undergraduate EFL learners sociocultural competence.

Skype is regarded as a communication tool that allows users to make audio and video calls over the Internet. It is reported that in 2010, Skype had 124 million users who placed 95 billion calls 
in the first half of 2010, of which approximately 40\% were video calls (Melanson, 2010). Educators have been incorporating Skype into their classrooms for a number of years now (Davis, 2006; Mirtschin, 2008; Smith, 2009a, 2009b; Stephenson, 2009; Waters, 2008). Skype can improve students' English and computer literacy while giving them the opportunity to explore other cultures, personalities, and varieties of spoken English (Ryobe, 2009).

In the second language classroom, Skype can be used to provide a variety of authentic learning experiences to students, including an interview with native speakers of the target language, or an international collaborative project with other classrooms (Eaton, 2010). Thus, it is a natural fit for language educators interested in having cross-cultural exchanges with students using Skype. More importantly, Lu, Goodale, \& Guo (2014) showed that online synchronous videoconference with native English speakers had positive impacts on Chinese participants' English pronunciation, oral fluency and, productivity in English.

The problem explored in this study stems from the researchers' experience and observations in foreign language classes as students and teachers, and others' experiences that have shown that many EFL students face difficulties in handling language efficiently and effectively whenever they are put in real-life or life-like situations. We think that this problem might be due the fact that English is taught traditionally and artificially without using any technology that gives students a chance to acquire authentic English in real-life situations. Being linguistically competent does not guarantee successful communication. We believe that teaching English language through traditional ways may not encourage and help EFL students to use it naturally in the way it is actually used by its people. We believe that English as a foreign language should be taught exactly in the way it is actually used by the native speakers of English. Accordingly, EFL students need more exposure to authentic English materials; English variations and in real-life situations. EFL class environments are often not well prepared for interaction. Accordingly, this study tried to investigate the effect of using CMC and specifically web-cam chat, on developing the sociocultural competence of university EFL learners. Many researchers regard web-cam chat as an effective tool in teaching language skills, language components, and language mechanics. Accordingly, this study tries to investigate its effect on the main competence of language that is the socio-cultural competence; this field is not investigated efficiently in Jordan.

The purpose of the study is to add to the scholarly literature on the impact of using web-cam chat on university EFL learners' sociocultural competence, and investigate the effect of using web-cam chat on EFL learners' productive and receptive skills when they interact appropriately in culturally communicative settings. This study integrated technology as one of the delivery systems to determine whether CMC can serve as a potential channel to deliver authentic culture to EFL learners.

The study is significant in the sense that the findings of the study might be officially adopted by The Ministry of Education and Ministry of Higher Education in Jordan to use web-cam chat in teaching foreign languages. In addition, teachers may use other techniques in their teaching, which may help them change their daily routine of teaching through using modern technology. Finally, curricula designers may benefit from this study, in the sense that they may select 
different types of web site chat rooms for developing other competencies of language, such as pragmatic, strategic, discourse, and aesthetic competencies.

Accordingly, the results of this study may encourage foreign language teachers, supervisors, curricula designers, textbook writers, and methodologists to look for effective techniques that give students a chance to acquire the sociocultural aspects of language more efficiently and effectively. Therefore, this study focused on investigating the effect of using web-cam chat on EFL learners' sociocultural competence. It suggestes that web-cam chat might be one of the practical techniques to improve the teaching of the cultural content. Additionally, this experimental study tried to investigate the effect of using wed-cam chat on the learners' sociocultural competence.

\subsection{Questions of the Study}

The following research questions were addressed in this study:

Q1: Are there any statistically significant differences between the mean scores of the experimental and control groups in the sociocultural competence of language due to the method of teaching (web-cam versus regular communicative method)?

Q2: Are there any statistically significant differences between the mean scores of the experimental group's learning of each sociocultural aspects of language (social, educational and religious, historical and geographical, sport and entertainment, nonverbal and prosodic, political and economic, and literary and aesthetic) as a result of using web-cam chat?

Q3: Are there any statistically significant differences between the mean scores of the experimental group students' performance in receptive and productive skills as a result of using web-cam chat?

\subsection{Hypothesis of the Study}

Three broad hypotheses are investigated in this thesis:

H1: There are no statistically significant differences between the experimental and control groups mean scores in the measure of sociocultural competence due to the method of teaching (web-cam chat versus regular communicative method) at $\alpha \leq 0.05$.

H2: There are no statistically significant differences between the mean scores of the experimental group's learning of each sociocultural aspect of language (social, political and economic, literary and aesthetic, nonverbal and prosodic, educational and religious, historical and geographical, and sport and entertainment) as a result of using web-cam chat at $\alpha \leq 0.05$.

H3: There are no statistically significant differences between the experimental and control groups' mean scores in the measures of receptive and productive skills as a result of using web-cam chat at $\alpha \leq 0.05$.

\subsection{Limitation of the Study}

The following limitations of this study should be noted: First, the sample size was small and only included a selected group of individuals (i.e., undergraduate EFL learners at Al-alBayt 
University who registered for the Conversational Skills Course in the second semester of the academic year 2013-2014). Second, the duration of the study is limited to a period of 8 weeks. Third, the material of the study was purposefully chosen, in the sense that it was loaded with many and different sociocultural aspects of English language. Fourth, this study is limited to the sociocultural aspects of language (social, educational and religious, historical and geographical, sport and entertainments, nonverbal and prosodic, literary and aesthetic, and political and economic). Fifth, this study is limited to using web-cam. Sixth, the Conversational Skills course teacher taught the control group whereas we taught the experimental group.

\section{Review of Related Literature}

This section is concerned mainly with the role of CMC in learning and how CMC affects EFL learners sociocultural competence.

Lee (1998) investigated the use of a combination of Internet technologies online newspapers and online chat rooms to enhance the learning of advanced Spanish students. The goals of the project were to (a) create opportunities for students to read authentic materials and gain cultural knowledge via online newspapers, (b) enhance intercultural exchanges via online chat rooms, and (c) improve students' writing and speaking skills as well as promote collaborative learning among students. The findings of the study revealed that the Internet does not only provide a powerful pedagogical tool but also supports an interactive methodology that truly enlarges students' imagination and ingenuity as they communicate with others in the real world. The positive results of the study indicated that foreign language teachers could well explore and experiment with the application of combined Internet resources for advanced language students.

Liaw (2006) investigated the extent to which e-learning can develop EFL learners' intercultural competence. The purpose of the project was to foster EFL students' intercultural competence by having them read articles on topics of their own culture and communicate their responses with speakers of another culture. The use of e-referencing tools showed a similar drastic decrease in number and this decrease of uses of the e- referencing tools was the same for all participants.

Pasfield-Neofitou (2007) examined the characteristics of Japanese-English intercultural Internet chat, the ways in which learners use this medium as an opportunity to communicate in their target language, and the strategies chat participants utilize. The focus of this paper was to examine the linguistic and interactional characteristics of Japanese-English intercultural Internet chat through one specific software application, the instant messenger MSN Messenger. The results of the study indicated that chat provided a positive environment in which to achieve goals of socialising and language learning in an intercultural context. Pasfield-Neofitou concluded that authentic intercultural chat communication is a fertile area for further investigation.

Ritchie (2009) investigated whether CMC intercultural exchange offers the conditions 
necessary for the development of the sociolinguistic competence of L2 learners. The secondary goal was to provide a description of the characteristics of the exchange as a language practice regarding language learning and cultural contact. The findings of this study suggested that intercultural CMC exchange offers positive conditions for the development of this competence.

Bataineh (2010) conducted an experimental study on the effect of instructional technologies on the sociocultural competence of the EFL learners. The findings of this study suggested that the tenth grade students of English had developed their cultural knowledge over 2 months of a semester through exposure to instructional technologies. Multimedia had an effect on the sociocultural competence of the learners, in the sense that it increased their overall cultural knowledge of the English language community.

Al-Issa (2011) investigated the effect of using videos on 11th grade EFL students' sociocultural competences. The aim of her study was to investigate the effect of using videos on making students more socioculturally competent. According to the results of the study, it was clear that scores of the experimental group were better than those of the control group, and the level of competence of the experimental group on the sociocultural aspects of language improved after exposure to authentic materials over 10 weeks, while there was no improvement in the competence of the control group. Al-Issa concluded that using videos had a positive effect on the sociocultural competence of the EFL students and that language cannot be taught without its culture.

Lothe (2011) examined how CMC-embedded web-quests developed online students' knowledge and understanding of German culture. Additionally, this study examined what mediating strategies were used by the online students of German in their asynchronous and synchronous online discussions of German culture that were part of their CMC-embedded web-quest tasks. These results highlighted the dynamic nature and potentiality of CMC-embedded web-quests that can be especially useful to teach culture, an often neglected aspect of FL instruction, and the importance of creating groups and peer interaction in distance EFL instruction. Additionally, findings of this study have implications for the purposes of the synchronous and asynchronous online discussions, culture model in FL instruction and design of CMC-embedded web-quests.

Bataineh (2014b) examined the effect of using web-cam chat on EFL learners' sociocultural competence. The results of the study showed there was a statistically significant difference in the arithmetic mean in the achievement test for the experimental group. It means that the experimental group performed better than the control group. The result of the study revealed that using web-cam chat alongside the traditional method has an effect on the EFL learners' sociocultural competence.

\section{Methodology}

\subsection{Participants of the Study}

The sample of the study consisted of 38 undergraduate EFL students who registered for the 
Conversational Skills Course during the second semester of the academic year 2013-2014 at Al-alBayt University. They were 20-22 years old. We assigned 20 students to the experimental group and 18 students to the control group...

\subsection{Design of the Study}

We used a pre- and posttest technique in this experimental study. Both groups were taught the same suggested material on the same days of the weeks. The Conversational Skills Course teacher taught the control group traditionally, while we taught the experimental group via web-cam chat. Both groups took the same test before and after the experiment to measure differences, if any, in the students' competencies. The experimental group was taught the suggested material using web-cam chat in which students interacted with native speakers of English in their cultural world. Additionally, through communication with native speakers via web-cam chat, students were involved in communicative oral activities. Then the experimental group students had web-cam chats among one another to internalize what they had acquired through chatting with native speakers of English. The control group was taught the same suggested material traditionally without using any technology. The pretest was administered by native speakers of English on topics that are related to cultural aspects of English language, and the posttest was administered in the same manner. The team of examiners were teachers who teach English language in Eqab Centre in Mafraq. To avoid subjectivity, a mean score was calculated by the team of examiners to each examinee.

\subsection{Instrumentation of the Study}

After analyzing the content of the intended prescribed textbook, we found that it did not cover many of the sociocultural aspects of language. Accordingly, we designed a suggested test loaded with various sociocultural aspects of English language in order to achieve the purpose of the study - to investigate the effect of using web-cam chat on undergraduate EFL learners' sociocultural competence. A team of experts in curricula, Instruction, CALL, and TEFL validated the suggested test. To achieve this purpose, students of both groups sat for a written and oral test at the beginning of the second semester of the academic year 2013-2014 to determine their actual sociocultural knowledge before starting the experiment. The test was based on the suggested syllabus. It consisted of two parts; written and oral tests. The written test measured the learners' ability in reading comprehension and writing skills; whereas the oral test measured their ability in speaking and listening skills. In the reading test, there was one passage followed by 25 questions, which were related to sociocultural aspects of language. In the writing test, students were asked to write two paragraphs from 50 to 70 words about two topics on sociocultural aspects of English. The examinees were also asked to re-order five sentences to make them grammatically and socioculturally well-formed. After 8 weeks, the same test was administered. The teacher informed the learners that neither the pretest nor the posttest would count to their final grades in the course. The pre/posttests were based on the cultural information contained in the suggested syllabus. The pre-post tests were administered by native speakers of English on topics related to cultural aspects of language. The test examined the learners' ability to function in a native community of English and communicate in a cultural context. 


\subsection{Validity of the Test}

A team of English language specialists and some others who are specialized in educational psychology, computer science, curricula, and philosophy of education validated the test. It was also given to a team of professors in TEFL, CALL, and linguistics to evaluate it and suggest changes. Remarks and recommendations of these experts were taken into consideration. They made important changes in the test and the materials of the study. They checked the test regarding the number of questions, distribution of scores, the content, form, spelling, grammar, meaning, and duration.

\subsection{Reliability of the Test}

One of the techniques that can be used to determine test reliability is the test-retest method. Thus, to establish the reliability of the tests, the test-retest technique was used. A random sample of 15 students was selected from the same department from which the study sample was drawn. They sat to the test. Two weeks later, the pilot group took the same test. In both administrations, favourable and identical conditions were secured concerning the place, time, clarification of each test item and discipline. By using Pearson's formula, the pilot administration of the test have shown that the correlation coefficient between students' ranks on both testing occasions were computed and found to be $93 \%$. Thus, the test can be described as being highly reliable. They gained scores of the participants in the two tests were analysed and compared using basic statistical descriptive tools, that is, calculation of the means and standard deviations. The results helped the researchers to (a) make sure of the clarity of the tested skills and their items, (b) determine the suitable level of difficulty of the items, (c) identify the discriminatory power of the test items, (d) estimate the tempting power of distracters, $€$ determine the reliability of the test, and (f) determine the average time needed to answer the test items.

\subsection{Variables of the Study}

The study has the following variables:

1. The independent variable of this study is the teaching method which included (a) teaching the sociocultural aspects by using web-cam chat, and (b) teaching the sociocultural aspects by using the regular communicative method.

2. The dependent variables were both groups' scores on the posttest and in each sociocultural aspect of language (social, educational and religious, historical and geographical, sport and entertainment, nonverbal and prosodic, political and economic, and literary and aesthetic) and language skills (reading, listening, speaking, and writing).

\subsection{Instructional Program}

The instructional program used in this study was Skype, which was available online. It was adopted due to its familiarity among students and its ease of use. It also allows anyone with an Internet connection and headset to communicate in the voice and/or video medium either one-to-one or in groups. Conversations carried out through Skype are much like conversations held by telephone. Thus, the choice of Skype was considered suitable for the synchronous 
CMC spoken interactions of this study because Skype's advanced features such as screen sharing, file transfer and instant messaging make this technology appropriate as a teaching tool, in addition to its use as a personal communication tool. Besides, in second language classrooms, Skype can be used to provide a variety of authentic learning experiences to students, including an interview with an author or other native speakers of the target language or international collaborative projects with other classrooms. The computer-based method in this study was limited to the use of Skype as a modern program that helps learners to contact and communicate between each other, and to develop the learners' productive skills. It also gave the students an opportunity to use voice chat, unlike other chat rooms that offer only text chat (Eaton, 2010).

Skype is a well-known video-chat program. Its users register under a unique, personal Skype name. The registered user is not required to set up more than a simple profile. Skype allows communication through a variety of ways including instant messaging, voice chat using a Voice Over Internet Protocol (VOIP), calls to landlines, and conference calls. The unique feature is its ability to provide synchronous videoconferencing. Video conference calls can handle up to 10 Skype members at once. Each Skype participant had a headset, separate microphone, or built in microphone along with a video capturing device (i.e. web-cam). The facilitator, once logged in, invited all participants to the group. Since the facilitator had a premium subscription to Skype, all members had access to all other participants' passport-sized real-time images along with the ability to hear each participant's voice. All participants could talk at the same time much like face-to-face interactions. Accordingly, the researchers tended to use Skype as a tool of the present study for its beneficial characteristics, which make it as a model among other programs (Eaton, 2010).

\subsection{Instructional Treatment}

Before the experiment, we explained the nature of the study and its goals for the learners. We introduced the experimental group to Web-cam and its applications in learning the sociocultural aspects of English via web-cam chat. Students were given a chance to ask questions about the course, techniques, and methods to be used in learning and teaching the sociocultural aspects of language. We prepared the students in the computer laboratory, which consisted of 40 computers. Each learner used one computer individually. The Skype program was installed on all computers.

We supplied each student with a nickname and password to log in and provided directions on how to sign in with their e-mail addresses. Then, the researchers prepared the scene for chatting. All students logged in and we helped them to add each other as groups. After that, the students began chatting with members of the English language community. Then students started chatting with each other to internalize deeply what they had acquired through chatting with native speakers of English to become part of their communication competencies in general and their sociocultural competence in particular.

Our role was observing the experimental group students' chat and communication, providing them with advice on how to use the program, and solving any problems that occurred while talking and listening. We encouraged students to communicate with native speakers to ensure 
that every student participated in the oral discussions. We chose topics from the selected units, and asked students to chat orally with native speakers on these topics. After chatting with native speakers on certain topics, students practiced chatting among themselves to internalize the sociocultural aspects that they have acquired through chatting with native speakers of English.

Meanwhile, in the control group the course teacher and students followed the regular communicative method described in the course textbook. It includes making face-to-face interaction, brainstorming, group work, and discussions without using any technology.

\subsection{Suggested Material}

With the help of a team of experts, we purposefully selected the course material because the prescribed course does not include some sociocultural aspects of language. Hence, the experts are specialized in teaching English languages who teach at Eqab Center (A centre for teaching English language) in Mafraq. The suggested material covered all sociocultural aspects of language. Students who participated in both the experimental and control groups of this study used the same suggested material loaded-with various sociocultural aspects of language, but it was presented using different methods. They studied two units of the suggested material. The focus was on different sociocultural aspects of language that include social, political and economic, literary and aesthetic, nonverbal and prosodic, educational and religious, historical and geographical, and sport and intertainment. The syllabus was on different topics related to British and American culture. These topics were intentionally chosen to cover all the sociocultural aspects of language nonverbal.

\subsection{Study Procedures}

The present study was conducted during the second semester of the academic year 2013-2014 at Al-al-Bayt University. The following procedures were followed after the researchers got the approval of the Faculty of Art--Department of Language and Literature to conduct this study. This department was selected intentionally because it has up-to-date laborites provided with Internet connection, and for other logistic purposes.

\section{Findings of the Study}

To determine the difference in the means scores of the two groups, a pretest was administered at the beginning of the second semester of academic year 2013-2014 to know the level of competence of the students in both groups before starting the experiment. As demonstrated in Table 1, there was no significant difference between the experimental and control groups at the beginning of the study.

\subsection{Findings Related to the First Research Question}

The first question of the study is -Are there any significant differences between the mean scores of the experimental and control groups on the measure of sociocultural competence due to the method of teaching (i.e., web-cam versus regular communicative method). To answer this question, means and standard deviations of the two groups for the method of teaching were 
calculated (see Table 1).

There was a significant difference in the sociocultural competence between the two groups in the posttest in favour of the experimental group. Accordingly, the hypothesis of the study, which read," Web-cam has an effect on the sociocultural competence of FL learners" was confirmed. It is obvious from Table 1 that the mean score of the experimental group on the posttest was higher than that of the control group. We attributed this difference to the method of teaching.

Table 1. Means and Standard Deviation of the Experimental and Control Groups on the Preand Posttests

\begin{tabular}{llllllll}
\hline Test & Group & $\mathrm{N}$ & Mean & $\begin{array}{l}\text { Std. } \\
\text { Deviation }\end{array}$ & $t$ & Df & Sig. \\
\hline Pre test & Control & 18 & 43.79 & 13.63 & 0.26 & 35 & 0.79 \\
& Experimental & 20 & 44.96 & 13.39 & & & \\
\multirow{2}{*}{ Post test } & Control & 18 & 49.71 & 13.97 & & & \\
& Experimental & 20 & 65.51 & 14.84 & 3.32 & 35 & 0.00 \\
\hline
\end{tabular}

\subsection{Findings Related to the Second Research Question}

The second question of the study was -Are there any statistically significant differences between the mean scores of the experimental and control groups' learning of each of the sociocultural aspects of language (social, educational and religious, historical and geographical, sport and entertainment, nonverbal and prosodic, political and economic, and literary and aesthetic) as a result of using Web-cam chat?

To answer this question one-way ANOVA were applied to the sociocultural aspects of language (social, political and economic, literary and aesthetic, nonverbal and prosodic, educational and religious, historical and geographical, and sport and entertainment) for the pre- and postassessments (see Tables 2 and 3).

Table 2 shows that there were significant differences between the experimental and control groups performance on the measure of sociocultural aspects of language, where all the $f$ values on the posttest are statistically significant in favour of the experimental group.

According to the results, it was clear that scores of experimental group were significally higher than those of control group, and the level of the experimental group on the sociocultural aspects of language improved after exposure to the authentic materials over 6 weeks, while there was no improvement in the level of the control group. Therefore, it can be concluded that web-cam has a positive effect on students' performance of the sociocultural aspects of language. 
Table 2. Pre- and-Posttest Results of Both Groups in Sociocultural Aspects of Language

\begin{tabular}{|c|c|c|c|c|c|c|c|c|c|c|c|}
\hline \multirow{2}{*}{$\begin{array}{l}\text { Sociocultural } \\
\text { aspects of } \\
\text { Language } \\
\end{array}$} & \multirow[b]{2}{*}{ Test } & \multicolumn{5}{|c|}{ Experimental group } & \multicolumn{5}{|c|}{ Control group } \\
\hline & & Mean & $\begin{array}{l}\text { Std. } \\
\text { Deviation }\end{array}$ & ANOVA & df & Sig. & Mean & $\begin{array}{l}\text { Std. } \\
\text { Deviation }\end{array}$ & $\begin{array}{l}\text { ANOV } \\
\text { A }\end{array}$ & df & Sig. \\
\hline Social out of & Pre & 19.70 & 5.53 & \multirow[t]{2}{*}{-7.70} & \multirow[b]{2}{*}{18} & \multirow[b]{2}{*}{0.00} & 19.77 & 6.00 & \multirow[t]{2}{*}{-5.84} & \multirow{2}{*}{17} & \multirow{2}{*}{0.00} \\
\hline $40 \%$ & Post & 28.37 & 6.86 & & & & 21.34 & 6.29 & & & \\
\hline $\begin{array}{l}\text { 2. Politic } \\
\text { al and economic }\end{array}$ & Pre & 3.94 & 1.52 & \multirow[t]{2}{*}{-7.34} & \multirow{2}{*}{18} & \multirow{2}{*}{0.00} & 3.85 & 1.64 & \multirow[t]{2}{*}{-4.99} & \multirow{2}{*}{17} & \multirow[b]{2}{*}{0.00} \\
\hline $\begin{array}{l}\text { out } \\
\text { of } 10 \%\end{array}$ & Post & 5.36 & 1.63 & & & & 4.66 & 1.63 & & & \\
\hline \multirow{2}{*}{$\begin{array}{l}\text { 3. Nonverbal and } \\
\text { prosodic out of } \\
10 \%\end{array}$} & Pre & 3.88 & 1.48 & \multirow{2}{*}{-6.14} & & & 3.56 & 1.44 & \multirow{2}{*}{-6.10} & & \\
\hline & Post & 4.93 & 1.72 & & 18 & 0.00 & 4.44 & 1.39 & & 17 & 0.00 \\
\hline \multirow{2}{*}{$\begin{array}{l}\text { 4. Educational } \\
\text { and } \\
\text { religious } \\
\text { out of } 10 \%\end{array}$} & Pre & 4.58 & 1.52 & \multirow[b]{2}{*}{-17.78} & \multirow[b]{2}{*}{18} & \multirow[b]{2}{*}{0.00} & 4.32 & 1.41 & \multirow[b]{2}{*}{-7.10} & \multirow[b]{2}{*}{17} & \multirow[b]{2}{*}{0.00} \\
\hline & Post & 7.81 & 1.10 & & & & 5.14 & 1.49 & & & \\
\hline \multirow{2}{*}{$\begin{array}{l}\text { 5. Historical and } \\
\text { geographic al out } \\
\text { of } 10 \%\end{array}$} & Pre & 4.56 & 1.64 & \multirow[b]{2}{*}{-11.16} & & & 4.58 & 1.62 & \multirow[b]{2}{*}{-10.69} & \multirow[b]{2}{*}{17} & \multirow[b]{2}{*}{0.00} \\
\hline & Post & 7.30 & 1.86 & & 18 & 0.00 & 5.42 & 1.52 & & & \\
\hline \multirow{2}{*}{$\begin{array}{l}\text { 6. Sport and } \\
\text { entertainment ou } \\
\text { of } 10 \%\end{array}$} & Pre & 4.63 & 1.54 & \multirow[t]{2}{*}{-16.39} & \multirow{2}{*}{18} & 000 & 4.31 & 1.22 & & 17 & \\
\hline & ${ }^{t}$ Post & 6.90 & 1.40 & & & 0.00 & 4.46 & 1.22 & -7.57 & 17 & 0.00 \\
\hline 7. Literary and & Pre & 3.67 & 1.09 & & & & 3.42 & 1.27 & & 17 & \\
\hline $10 \%$ & Post & 4.85 & 1.21 & -12.07 & 18 & 0.00 & 4.27 & 1.17 & -9.30 & & 0.00 \\
\hline $\begin{array}{l}\text { The average } \\
\text { score out of }\end{array}$ & Pre & 44.96 & 13.39 & & & & 43.79 & 13.63 & & & \\
\hline $100 \%$ & Post & 65.51 & 14.84 & -12.73 & 18 & 0.00 & & & -13.30 & 17 & 0.00 \\
\hline
\end{tabular}

Table 3. The Both Groups Students Results in Each Sociocultural Aspect of Language on the Posttest

\begin{tabular}{|c|c|c|c|c|c|c|c|}
\hline $\begin{array}{l}\text { The sociocultural } \\
\text { aspects }\end{array}$ & Group & $\mathrm{N}$ & Mean & $\begin{array}{l}\text { Std. } \\
\text { Deviation }\end{array}$ & ANOVA & $\mathrm{df}$ & $\begin{array}{l}\text { Sig. (2- } \\
\text { tailed) }\end{array}$ \\
\hline \multirow{2}{*}{ Social Out of $40 \%$} & Experimental & 20 & 28.37 & 6.86 & \multirow[t]{2}{*}{3.24} & \multirow{2}{*}{35} & \multirow{2}{*}{0.00} \\
\hline & Control & 18 & 21.34 & 6.29 & & & \\
\hline \multirow{2}{*}{$\begin{array}{l}\text { Political and } \\
\text { economic out of } \\
10 \%\end{array}$} & Experimental & 20 & 5.36 & 1.63 & \multirow{2}{*}{1.30} & \multirow{2}{*}{35} & \multirow{2}{*}{0.20} \\
\hline & Control & 18 & 4.66 & 1.63 & & & \\
\hline \multirow{2}{*}{$\begin{array}{l}\text { Nonverbal and } \\
\text { prosodic out of } \\
10 \%\end{array}$} & Experimental & 20 & 4.93 & 1.72 & \multirow[t]{2}{*}{0.96} & \multirow[t]{2}{*}{35} & \multirow[t]{2}{*}{0.34} \\
\hline & Control & 18 & 4.44 & 1.39 & & & \\
\hline \multirow{2}{*}{$\begin{array}{l}\text { Educational and } \\
\text { religious out of } \\
10 \%\end{array}$} & Experimental & 20 & 7.81 & 1.10 & \multirow[b]{2}{*}{6.20} & \multirow[b]{2}{*}{35} & \multirow[b]{2}{*}{0.00} \\
\hline & Control & 18 & 5.14 & 1.49 & & & \\
\hline
\end{tabular}




\begin{tabular}{|c|c|c|c|c|c|c|c|}
\hline \multirow{2}{*}{$\begin{array}{l}\text { Historical and } \\
\text { Geographical out } \\
\text { of } 10 \%\end{array}$} & Experimental & 20 & 7.30 & 1.86 & \multirow{2}{*}{3.34} & \multirow{2}{*}{35} & \multirow{2}{*}{0.00} \\
\hline & Control & 18 & 5.42 & 1.52 & & & \\
\hline $\begin{array}{l}\text { Sport and } \\
\text { entertainment }\end{array}$ & Experimental & 20 & 6.90 & 1.40 & \multirow[t]{2}{*}{5.64} & \multirow[t]{2}{*}{35} & \multirow[t]{2}{*}{0.00} \\
\hline out of $10 \%$ & Control & 18 & 4.46 & 1.22 & & & \\
\hline \multirow{2}{*}{$\begin{array}{l}\text { Literary and } \\
\text { aesthetic out of } \\
10 \%\end{array}$} & Experimental & 20 & 4.85 & 1.21 & \multirow{2}{*}{1.47} & \multirow{2}{*}{35} & \multirow{2}{*}{0.15} \\
\hline & Control & 18 & 4.27 & 1.17 & & & \\
\hline \multirow[t]{2}{*}{$\begin{array}{l}\text { The average score } \\
\text { out of } 100 \%\end{array}$} & Experimental & 20 & 65.51 & 14.84 & \multirow[t]{2}{*}{3.32} & \multirow[t]{2}{*}{35} & \multirow[t]{2}{*}{0.00} \\
\hline & Control & 18 & 49.71 & 13.97 & & & \\
\hline
\end{tabular}

\subsection{Findings Related to the Third Question}

The third question of the study was "Are there any statistically significant differences between the mean scores of the experimental group students' performance in receptive and productive skills as a result of using web-cam chat?" To answer this question, one-way ANOVA and Scheffe tests were applied for the means of the two groups on (reading, writing, speaking and listening) for the pre- and posttests (see Table 4).

Table 4. The Posttest Results of the Experimental Groups in Language Skills

\begin{tabular}{llllll}
\hline Skill & Mean & Std. Deviation & Scheffe & Df & $\begin{array}{l}\text { Sig. } \\
(\mathrm{p})\end{array}$ \\
\hline Reading & 17.03 & 2.99 & 1.933 & 34 & .062 \\
Writing & 14.29 & 3.54 & 2.23 & 35 & .032 \\
Listening & 14.32 & 4.35 & 4.05 & 35 & .000 \\
Speaking & 19.87 & 4.26 & 4.82 & 35 & .000 \\
Total & $\mathbf{6 5 . 5 1}$ & $\mathbf{1 4 . 8 4}$ & 3.32 & $\mathbf{3 5}$ & $\mathbf{. 0 0 2}$ \\
\hline
\end{tabular}

\section{Discussion of the Results}

\section{Question 1}

The first question investigated if there were any significant differences between the mean scores of the experimental and control groups in the sociocultural competence due to the method of teaching (Web-cam vs. regular communicative method).

According to the findings of this study, Web-cam was found to offer a good opportunity for teaching the sociocultural aspects of language implicitly. Additionally, the results of our study showed that university EFL learners improved and developed their sociocultural competence over 8 weeks of exposure to Web-cam that included many and different sociocultural aspects of language. 
The results of the study also showed that the experimental group achieved better than the control group, thus, using Web-cam can be regarded as an effective technique to improve the EFL learners' sociocultural competence. It was clear also that students' knowledge of the social, educational and religious, historical and geographical, and sport and entertainment was stronger than their knowledge in the nonverbal and prosodic, political and economic, and literary and aesthetic aspects. This finding might be due to students' individual interests or that they found some aspects more challenging than others.

These findings align with the results of many studies that have discussed the importance of using different types of technology in teaching the sociocultural aspects of language, such as; Brooks (1989); Herron (1999); Cunning (2000); Rammal (2006); Wilcox(2009); Albirini (2009); and Bataineh (2009). The results are also in harmony with Ko (2012), who investigated the impact of synchronous CMC learning environments on learners' perception of social presence.

After analyzing the experimental group students' comments on their new experiences of studying via Web-cam chat, the researchers understood that using Web-cam was found to be interesting in education in general and in learning and teaching English language in particular; students enjoyed using a computer for a long time, practicing language and communicating with others via different global sites of social communication, one of which is web-camera through Skype. Communication about computer use helped students' parents to change their attitudes and philosophy towards using computers in English class; for many reasons students were no longer shy, reluctant, and afraid. Sheeks and Birchmeier (2007) adopted the same idea as they found that shy individuals developed good social relationships using asynchronous text-based chat. This can be attributed to many reasons; when language learners' communicative language skills are enhanced, students feel refreshed and comfortable as they leave their classroom and go to the computer laboratory, which may reduce the monotony of the English class and stimulate students' abilities and encourage them to spend more time in front of a computer screen practicing communication skills. More importantly, students tried a new experience and atmosphere for learning that enabled them to acquire English language quickly, freely, and more effectively than studying traditionally. These results are also consistent with Cheng, Krumwiede, and Sheu, (2009), who compared online audio group discussion with face-to-face traditional method, where the results revealed that participants were more willing to express their opinions, ideas, and thoughts. Compared with online typing, the use of speaking leads participants to have greater satisfaction and self-disclosure. Online audio chat produced results that were superior to those that can be achieved in other contexts. Additionally, findings showed that CMC online learning had positive effects on learning operation. This finding is in line with what was discovered by Olaniran (2006), whose preliminary findings in the research on synchronous, text-based CMC online learning programs were positive.

By the same token, Web-cam was found to be a good tool for creating successful learning outcomes. This finding agreed with Allen and Seaman (2003), which assumed that CMC has been found to be effective for chatting language outcomes. CMC allowed students to exchange their experiences and thoughts in a comfortable and relaxed atmosphere. In addition, students incorporated different topics such as eating habits, food preferences, personal cooking styles, 
and restaurants of their choice. This result is identical with that of Hrastinski (2008), who claimed that synchronous CMC interactions stimulate -psychological arousal since the -real time chats resembled -real-life situations consequently students found it acceptable to exchange personal information (identity, past experiences, feelings, personal stories, and experiences). We can hence deduce that synchronous CMC may have cognitive as well as affective benefits for online FL learners.

The findings of the study revealed Web-cam as an effective tool that had a significant role in enhancing learners' knowledge and ability to understand culture and sense of community. This view agrees with the findings of Lothe (2011), who demonstrated the efficacy of CMC-embedded web-quests, which had a significant role to play in enhancing students" knowledge and understanding of German culture, and had cognitive and affective benefits. More specifically, the study findings indicated that the CMC-embedded web-quests were successful in enhancing students' knowledge and understanding of German culture, which can be especially challenging in distance FL courses and underscore the importance of culture in FL instruction. This study also highlighted the importance of creating groups and peer interaction especially in online FL courses, to create a sense of community and foster a sense of belonging to the group.

CMC tools such as Web-cam supply university students with new opportunities for learning L2 in and out of their classroom. Many research findings have shown that the use of technology in EFL classrooms can have a positive impact on attitudes towards learning because the use of CMC provides additional practice, a sense of community and non-threatening learning environment, and integrates sound, graphics, motion, colour, and different skills. We interpreted the learners' comments on their new experience and discovered that students enjoyed using computers, found it useful and interesting, and considered it a new way of learning and doing homework. It raised their motivation. It created a warm climate between the students and instructor and among the students themselves. They were able to use it any time and as many times as they needed.

\section{Question 2}

The second question sought to determine whether (Are there any statistically significant differences between the mean scores of the experimental group's performance of the sociocultural aspects of language as a result of using Web-cam chat. The findings of the study revealed that using Web-cam in a language-learning environment has numerous benefits including promoting meaningful human interactions that can foster the learning process, cultivating social relationships, and creating a relaxing environment. This result is in harmony with what is reported by Bataineh (2014c), who concluded throughout his study that using web-cam chat alongside the traditional method has great effect on the sociocultural competence of FL learners. Further results of Batainehs study showed that using Web-cam can be regarded as an effective technique to improve FL students' sociocultural competence.

In conclusion, there was no significance difference in students' achievement in the posttest regarding the nonverbal and prosodic, political and economic, and literary and aesthetic aspects of language, because they are different from one language community to another. Accordingly, 
and with the help of the findings of contrastive linguists, we might be allowed to say that students faced difficulties in the mastery of these sociocultural aspects of English because they differ from their native language. This might be due to the fact that the wider the gap between L1 and L2, the more difficulties students are expected to face, and the more errors they expected to make.

\section{Question 3}

The third question tried to explore (Are there any statistically significant differences between the mean scores of the experimental group students' performance in the (receptive and productive) skills as a result of using Web-cam chat?

According to the findings of this study, Web-cam was found to offer a great opportunity in teaching receptive and productive skills. Students developed in all the language skills in general, and in speaking and listening skills in particular. In other words, students got better results on the speaking and listening tests in a using Web-cam chats.

The findings of the study revealed that the experimental group students acquired both skills (speaking and listening) in a CMC environment. This might refer to many factors. Firstly, students might find it interesting to express their opinions in speaking because in such noncurricular and informal environment, students might be found un reluctant to express their opinions, and feelings freely without having any hesitation or fear. They were not told about every mistake they commit in speaking. Moreover, the main concern or purpose of speaking is conveying the message to the group regardless of how many syntactic and semantic mistakes are committed in transferring the message. In addition, the role of videoconferencing technology helped to develop listening comprehension skills where the students were engaged in a multi-modal approach of learning and teaching target language. These results go with the results reported by Glisan, Dudt, and Home (1998). Moreover, CMC also developed students' performance in listening skills. This might be attributed to the fact that students might concentrate more, benefit from their mates, and discover their errors and mistakes in a CMC environment.

This finding is in line with what was reported by Hals et al. (2009) who argued that EFL learners participate more equally in a discussion in a CMC environment. Therefore, $\mathrm{CMC}$ gave learners the opportunity to interact with target-language speakers and practice-speaking skills using web-cam chat. Skype is regarded an effective tool for language teaching and learning. Moreover, this tool is beneficial to beginners who try to learn English language effectively, and for teachers' effective teaching of English language. In addition, Skype's focus is on students' use of the web-cam during the pedagogical oral interactions. More importantly, it was used by students to carry their conversations in the computer lab. However, these results are in line with Mahdi (2014) who indicated that using Skype for the oral CMC group created turn-taking patterns that were very close to face-to-face turn taking.

According to the findings of this study, the researchers found out that the experimental group students have developed a lot in listening and speaking skills. This might be due to the effect of Web-cam chat through which the experimental group students interacted a lot with native 
speakers of English. Accordingly, it is unsurprising to find the experimental group' students more able to express their views, opinions, and feelings fluently, expressively, and amazingly.

Skype video activity was effective and useful. In addition, it gave opportunity to communicate with native speakers. Moreover, it was slightly stressful due to technical, pairing, and scheduling issues. Nevertheless, it was a new and enriching experience for the students, teachers, as well as the researchers. Therefore, these results were in harmony with what is reported by Ryobe (2009) whose study suggested that the Skype activity achieved the objectives of motivating students to practice oral communication and enhancing their interest in people from around the world. It improved the students' English and computer literacy while giving them the opportunity to explore other cultures, personalities, and varieties of spoken English.

Additionally, throughout the time of the experiment, Web-cam was a good way for creating an interactive learning environment. It helped developing the speaking skill in English language where students and teachers alike exchange various subjects and different levels. This result goes with that of Bataineh (2014 a) who revealed that students acquired the aspects of fluency when they learn English via CMC. The findings also indicated that CMC can play an important role in teaching the aspects of language fluency. It revealed as well that audio-visual chat had a great effect on the learners, in the sense that it increased their overall knowledge of the English language community and its culture.

Besides, this result is in line with what claimed by Hubbard (2004) who suggested that CMC tools such as Internet telephony, audio and video conferencing, voicemail, or voice discussion board can all be used to promote learners' speaking proficiency. By engaging learners in tasks of recording speech and sending files to other learners, communicative speaking skill can be a goal to achieve. In terms of the effect of CMC on language proficiency, many researchers have proposed its positive effect on the development of the learners' language proficiency.

This finding may be attributed to the fact that students might communicate with other classmates in the Internet chat that is a relaxing atmosphere, which might help them in developing their fluency and accuracy as well. These findings are in line with Xiao (2007) that participants using Internet-based desktop videoconferencing in the experimental group outperformed the L2 students in the control group throughout the treatment in terms of fluency and accuracy. Similarly, Satar and Ozdener (2008) supported these findings and reported that synchronous CMC enriches speaking proficiency levels of the students in the voice chat group and reduces language anxiety levels of the students in both the text and voice chat groups.

Moreover, this finding is in harmony with Mahfouz and Ihmeideh (2009) who pointed out that students' attitudes toward using text chat with anonymous native speakers of English for improving their English language skills are higher concerning speaking skills, followed by listening skills, reading skills, and finally writing skills.

This result is consistent with what was reported by Satar and Ozdner? (2008), who investigated the use of two synchronous computer-mediated communication tools: Text and voice chat on speaking proficiency and anxiety. The results showed that the speaking proficiency of both 
experimental groups increased, whereas there was a decrease in the anxiety levels for the text chat groups. This result is also in harmony with what is reported by Sahin (2009) who indicated that learning in CMC environment develops EFL learners' ability in vocabulary acquisition. This finding is also in line with Shang (2007) who argued that computer-based exchanges with peers at least four times have a greater improvement on the participants' writing performance. Also, this finding is in harmony with what is reported by Cumming (2004) who observed that in the online course for EFL writers, students' essays are more developed, more unified, more coherent, or general more free from error than those of their face-to-face counterparts.

This result is also in harmony with what is reported by Blake (2009) that the Internet chat group demonstrated higher average gain scores on all five measures when compared to the control group and higher average on all measures when compared to the face-to-face group for improving oral fluency in second language. The results showed that learners who used the Internet chat method could develop students' performance in speaking skills. Internet chat developed their speaking skills more than those who simply attended face-to-face interaction lessons without using this method.

In addition, these findings are in line with Jaya (2008) who reported that the voice modes of Skype are said to be helpful in language learning, especially speaking skill. Skype provided learners with the opportunity to interact with target-language speakers. Moreover, it helped to develop students' proficiency. Finally, the results are in line with Payne and Whitney (2002), who reported that L2 oral proficiency can be indirectly developed through chat room interaction in the target language.

More importantly, online listening played a very important role in tasks that required students to activate more learning resources than is the case with text-based tasks and adopted a deep, integrative approach to learning. Besides, online listening tasks in L2 could lead to greater retention of information and vocabulary, and this greater retention of information and vocabulary can lead to noticeable cross modality gains. These results are in line with the results reported by Absalom and Rizzi (2008) who emphasized on the importance of online learning in creating a motivational environment that enables learners to acquire lexicons easier and faster than acquiring them traditionally.

Furthermore, this finding in line with a case study conducted by Nomass (2013) who reviewed briefly how technology can be utilized in developing the language skills of the learner. The results of her study showed that most of the students preferred the use of technology, especially computers, in developing their second language skills.

Moreover, the results of the study showed the new experience successfully motivated students, developed their intercultural awareness, and improved their oral communication abilities. Moreover, the primary goal of the study was to provide an environment that would motivate university students to widen their pedagogical horizons through autonomous and intercultural awareness by engaging students in Skype video chat to improve their English sociocultural competence. These results are in harmony with the results reported by Canale and Swain (1980) who reveled that Skype is an effective tool for developing students' intercultural awareness. 
Finally, the researchers would like to say that besides the sociocultural competence, Web- cam chat has a great effect on developing students fluency, accuracy and proficiency as well. Moreover, it helps in developing students language skills in general and the (receptive and productive) skills simultaneously. What is more, it develops language student' mechanics of speaking and writing.

\section{Conclusion}

It could be concluded that Web-cam chat is so important in teaching English language because it can help students learn more about the cultural aspects of language. The findings of this study, from theoretical and empirical point of view, suggested that the cultural component of EFL, if taught and learned adequately, would be beneficial for learners in terms of language skills, cultural awareness, and attitudes.

Web-cam had a positive effect on the sociocultural competence of EFL undergraduate learners. Moreover, language cannot be taught without its sociocultural aspects. Therefore, the sociocultural competence should be highly considered in EFL classes.

The following conclusions could be derived from this study:

1. Internet Web-cam chat activities could be supportive to the learning of speaking, listening, reading, and writing skills.

2. Learning through Web-cam chat is more permanent due to the use of various tools such as sounds, texts, cameras, microphones, and computer screen.

3. Web-cam chat enables the individual to advance according to his own learning speed by taking into consideration the characteristics of the individual.

4. The educational environments in which Internet Web-cam applications are realized in the classroom are highly motivating environments for success and learning, especially learning the productive skills.

\section{Recommendations}

We recommend that Web-cam chat can be adapted to most classes, in teaching language skills, components, mechanics and competences that include pragmatic, strategic, sociocultural, aesthetic, discourse, nonverbal, and prosodic competences. These competences are at most ignored in EFL classes. There is no full understanding of any verbal or graphic message without considering these competences. Accordingly, the researchers recommend using the contemporary instructional technologies for teaching language skills, components, mechanics, and competencies such as Web-cam.

Besides, Ministries of education and higher education should equip schools and universities with special rooms supplied with computers, Internet services and Wed-Cams, so that students will have a chance to enter chat rooms and communicate among eachother and with native 
speakers of English as well. In addition, students and teachers will be able to watch and listen to real-life situations and authentic materials. Ministries of education and higher education should encourage schools and universities to train teachers of English to deal with computers, Internet applications like chat rooms.

In addition, curricula designers should take into account the importance of Web-cam, and involve in the textbooks different authentic subjects and topics related to the sociocultural aspects of language. EFL curricula designers should recommend using new syllabuses authentic materials that develop the EFL learners' ability of expressing facts, ideas and feelings within their sociocultural context. Such materials should be successfully and purposefully chosen in such a way that they should be more testable, interesting, and motivating. Textbook writers should include in EFL syllabuses CDs and DVDs that contain everyday life settings and situations of English language community such as; greetings, rewarding, excusing, inquiring, blaming, and exclaiming.

Finally, more researches should be conducted and applied to study the effect of CMC on EFL learners' sociocultural competence in longer periods, using different variables, and different techniques for teaching language skills in CMC environment and to other stages, and bigger samples of students in universities and public schools in order to make the results widely applicable.

\section{References}

Absalom, M., \& Rizzi, A. (2008). Comparing the outcomes of online listening versus online text-based tasks in university level Italian L2 study .ReCALL, 20(1), 55-66. http://dx.doi.org/10.1017/S0958344008000517

Albirini, A. (2009). Using technology, literature and guest speakers to raise the cultural awareness of Arabic language learners. The International Journal of Language, Society and Culture, 28, 1-15.

Al-Issa, S. (2011). The effect of using videos on EFL socio-cultural competence of eleventh grade learners in Ramtha directorate. (Unpublished Master's Thesis). Al-alBayt University, Mafraq, Jordan.

Allen, I. E., \& Seaman, J. (2003). Seizing the opportunity: The quality and extent of online education in the United States, 2002 and 2003. Wellesley, MA: Sloan Consortium.

Bataineh, A. (2002). An evaluation of the socio-cultural elements in the prescribed English textbooks of the secondary schools in Jordan and their affections the students' performance. (Unpublished doctoral dissertation). Baghdad University, Baghdad, Iraq.

Bataineh, A. (2009). An evaluation of the authentic socio cultural elements in the prescribed English language textbooks of the secondary schools in Jordan. An-Najah Univ. J. Res, (Humanities), 23(1), 289-324.

Bataineh, A. (2010). The effect of instructional technologies on the socio-cultural competence 
of the FL learners. ICIT Proceedings, 7(4), 12-14.

Bataineh, A. (2014a). The effect of using audio-visual chat on developing English as a foreign language learners' fluency and productivity of authentic oral texts. International Journal of Linguistics, 6(3), 85-108.

Bataineh, A. (2014b). The effect of using computer-mediated communication on English language learners' socio-cultural competence. International Journal of Interactive Mobile Technologies, 8(3), 44-55.

Bataineh, A., \& Al-Abdali, A. (2014). The effect of using web-cam chat on Jordanian English major students' paralinguistic competence. International Journal of Education, 6(2), 159-176.

Blake, C. (2009). Potential of text-based Internet chats for improving oral fluency in a second language. The Modern Language Journal, 93(2), 227-242. http://dx.doi.org/10.1111/j.1540-4781.2009.00858.x

Brooks, N. (1989). Teaching culture in the foreign language classroom. Foreign language Annals Journal, 1, 204-217. http://dx.doi.org/10.1111/j.1944-9720.1968.tb00135.x

Brown, H. D. (2007). Principles of language learning and teaching. New York, NY: Pearson Education.

Canale, M., \& Swain, M. (1980). Theoretical bases of communicative approaches to second language teaching and testing. Applied Linguistics, 1(1), 1-47. http://dx.doi.org/10.1093/applin/1.1.1

Cheng, C., Krumwiede, D., \& Sheu, C. (2009). Online audio group discussions: A comparison with face-to-face methods. International Journal of Market Research, 51(2), 219-241. http://dx.doi.org/10.2501/S1470785309200438

Cortes, N. (2007). Language meeting culture in the foreign language classroom. A comparative study. Interlinguistica, 17, 230-237.

Cumming, M. (2004). Because we are shy and fear mistaking: CMC with EFL writers. Journal of Basic Writing, 23(2), 23-48.

Cunning, C. (2000). Practical aspects of using video in the foreign language classroom. The Internet TESL Journal, 6(11), 27-33.

Davis, V. (2006). Using Skype in the classroom. Applied linguistics, 2(3), 11-26.

Eaton, S. (2010). Using Skype in the second and foreign language classroom. International Journal of Linguistics, 3(6), 31-41.

Elmes, D. (2013). The relationship between language and culture, National Institute of Fitness and Sports in Kanoya International Exchange and Language Education Centre. TESL Journal, 8(10), 17-23.

Glisan, G.; Dudt, K., \& Home, M. (1998). Teaching Spanish through distance education: 
Implications of a pilot study. Foreign Language Annals, 31, 48-66. http://dx.doi.org/10.1111/j.1944-9720.1998.tb01332.x

Gonen, S., Ipek, Initial \& Saglam, S. (2012). Teaching culture in the FL classroom: Teachers' perspectives. IJGE: International Journal of Global Education, 1(3), 26-46.

Hals, A. Schuh, K., \& Alessi, S. (2009) Native and non-native speakers in online and face-to-face discussion: Leaving the playing field. Educational Technology System, 30(4), 33-373.

Herron, C. (1999). The effectiveness of a video-based curriculum in teaching culture. Modern Language Journal, 83(4), 518-527. http://dx.doi.org/10.1111/0026-7902.00038

Hrastinski, S. (2008). The potential of synchronous communication to enhance participation: A case study of two e-learning courses. Information \& Management, 45(7), 499-506. http://dx.doi.org/10.1016/j.im.2008.07.005

Hubbard, P. (2004). Learner training for effective use of CALL. In S. Foots \& C.M. Browne (Eds.), new perspectives on CALL for second language classrooms. London, UK: Lawrence Erlbaum.

Jaya, R. (2008). Skype voice chat: A tool for teaching oral communication. Language in India, 8(12), 9-21.

Jurist, R. (1999). The promise of technology. Implications for business teacher Education in the 21 century: Meeting the challenges to business education (pp. 59-71). Reston, VA: National Business Education Association.

Ko. C. (2012). Can synchronous computer-mediated communication (CMC) help beginninglevel foreign language learners speak? Computer Assisted Language Learning, 25(3), 217-236. http://dx.doi.org/10.1080/09588221.2011.649483

Kramsch, C. (1998). Language and culture. Oxford, England: Oxford University Press.

Kuang, J. F. (2007). Developing students' cultural awareness through foreign language teaching. Sino-US English Teaching, 4(12), 74-81.

Lee, L. (1998). Going beyond classroom learning: Acquiring cultural knowledge via on-line newspapers and intercultural exchanges via on-lineonline chat rooms. CALICO Journal, 16(2), 101-120.

Liaw, M. (2006). E-learning and the development of intercultural competence. Language Learning \& Technology, 10(3), 49-64.

Lothe, R. (2011). Role of CMC-embedded web-quests in enhancement of online students' knowledge and understanding of German culture--A Case study. Oxford, England: Oxford Universty Press.

Lu, R.L., Goodale, T.A. \& Guo, Y.B. (2014) Impact of videoconference with native English speakers on Chinese EFL learners' oral competence and self-confidence. Open Journal of 
Social Sciences, 2(4), 54-60. http://dx.doi.org/10.4236/jss.2014.22008

MacKinnon, S. (2002). Technology integration in the classroom: Is there only one way to make it effective? Technologic, October - December 2002, 57-60.

Mahdi, S. (2014). The impact of computer-mediated communication environments on foreign language learning: A reviews of the literature, World Journal of English Language, 4(1), 9-19.

Mahfouz, S., \& Ihmeideh, F. (2011). Attitudes of Jordanian students toward using online chat discourse with native speakers of English for improving their language proficiency. Computer Assisted Language Learning, 22(3), 207-227. http://dx.doi.org/10.1080/09588220902920151

Melanson (2010). Skype files for initial public offering. Oxford, England: Oxford Universty Press.

Mirtschin, A. (2008). Using Skype in the classroom. Oxford, England: Oxford University Press. Mel

Muir, P. (2007). Toward culture: Some basic elements of cultural-based instruction in China's high schools. Sino-US English Teaching, 4(4), 38-43.

Nomass, B. (2013). The impact of using technology in teaching English as a second language. English Language and Literature Studies, 3(1).

Olaniran, B. A. (2006). Applying synchronous computer-mediated communication into course design: Some considerations and practical guides. Campus-Wide Information Systems, 23(3), 210-220. http://dx.doi.org/10.1108/10650740610674210

Pasfield-Neofitou, S. (2007). Intercultural Internet chat and language learning: A socio-cultural theory perspective, learning and socio-cultural theory: Exploring modern Vygotskian perspectives. International Workshop, 1(1), 7-12.

Payne, J., \& Whitney, P. (2002). Developing L2 oral proficiency through synchronous CMC: Output, working and Interlingua development. Calico Journal, 20(1), 32.

Qu' Y. (2010). Culture understanding in foreign language teaching. English Language Teaching, 3(4), 12-17. http://dx.doi.org/10.5539/elt.v3n4p58

Rammal S. (2006). Using video in the EFL classroom. Oxford, England: Oxford University Press.

Ritchie, M. (2009). Intercultural computer-mediated communication exchange and the development of sociolinguistic competence. Oxford, England: Oxford University Press.

Rivers, W. M. (1981). Teaching foreign language skills. Chicago, IL: The University of Chicago Press.

Ryobe, I. (2009). Using Skype and Moodle at the university level for supplementary oral communication practice. GLoCALL 2009 Proceedings. 
Sahin, M. (2009). Second language vocabulary acquisition in synchronous computer-mediated communication. Eurasian Journal of Educational Research, 34, 115-132.

Satar, H., \& Ozdner, N. (2008). The effects of synchronous CMC on speaking proficiency and anxiety: Text versus voice chat, The Modern Language Journal, 92(4).

Shang, H. (2007). An exploratory study of e-mail application on FL writing performance. Computer Assisted Language Learning, 20(1), 79-96. http://dx.doi.org/10.1080/09588220601118479

Sheeks, S., \& Birchmeier, P. (2007). Shyness, sociability, and the use of the computer-mediated communication in relationship development. Cyber Psychology \& Behaviour, 10(1), 64-70. http://dx.doi.org/10.1089/cpb.2006.9991

Smith, K. (2009). From the coal face - Skype in the classroom. Oxford, England: Oxford University Press.

Stephenson, N. (2009). The many roles of Skype in the classroom. Oxford, England: Oxford University Press.

Tang, R. (1999). The place of -culture in the foreign language classroom: A reflection. The Internet TESL Journal, 5(8), 35-40.

Wang, L. (2005). The advantages of using technology in second language education. T.H.E. Journa, 32(10), 38-42.

Watcyn-Jones (year) — add reference for Penguin book that is text for course.

Waters, S. (2008a, August 6). Quick start tips for new Skype users. Retrieved from http://theedublogger.com/2008/12/16/quick-start-tips-for-new-skype-users/

Wilcox, K. (2009). The impact of student beliefs on the effectiveness of video in developing cross-cultural competence. CALICO Journal, 27(1), 91-100. http://dx.doi.org/10.11139/cj.27.1.91-100

Xiao, M. (2007). An empirical study of using Internet-based desktop videoconferencing in an EFL setting. Oxford, England: Oxford University Press.

Zsuzsana, I. (2010). From theory to practice: Intercultural CMC in the L2 Classroom, TESOL Journal, 13(2), 143-166.

\section{Copyright Disclaimer}

Copyright for this article is retained by the author(s), with first publication rights granted to the journal.

This is an open-access article distributed under the terms and conditions of the Creative Commons Attribution license (http://creativecommons.org/licenses/by/3.0/). 